\title{
Diffusion of Innovation: Case of Co-Design of Cabins in Mobile Work Machine Industry
}

\author{
Asko Ellman 1,*(D) and Tarja Tiainen ${ }^{2}$ \\ 1 Faculty of Engineering and Natural Sciences, Tampere University, 33720 Tampere, Finland \\ 2 Faculty of Information Technology and Communication Sciences, Tampere University, \\ 33100 Tampere, Finland; tarja.tiainen@tuni.fi \\ * Correspondence: asko.ellman@tuni.fi
}

Received: 17 April 2019; Accepted: 9 May 2019; Published: 11 May 2019

\begin{abstract}
This paper describes the development of using virtual reality for work content in one application area over a decade. Virtual reality technology has developed rapidly; from walk-in CAVE-like virtual environments to head-mounted displays within a decade. In this paper, the development is studied through the lens of diffusion of innovation theory, which focuses not only on innovation itself, but also on the social system. The development of virtual technology is studied by one case, which is cabin design in the mobile work machine industry. This design process has been especially suitable for using virtual reality technology.
\end{abstract}

Keywords: virtual reality; cabin design; diffusion of innovation

\section{Introduction}

Communication between the members of a design team is recognized to be a problematic area in the product design process [1,2]. Product design is often difficult because it requires multi-professional co-operation, and the participants may have different assumptions about the design process and its results $[3,4]$. If professional designers and non-designers are not able to integrate their knowledge, they would not be able to jointly design a new product. Prior research highlights the importance of tools that support interactions between users and designers $[5,6]$.

Co-design here refers to a situation where product designers and users conduct the design process, so that both participating groups can stay in their expertise area [7]. The users can become part of the design team-as experts on the basis of their experiences, only if they are given appropriate tools for expressing themselves [8]. Cooperation is understood as an attempt to facilitate users, researchers and designers in creative joint action, so that they can explore and envision ideas, make and discuss sketches, and tinker with prototypes together [9]. The studies deal with alternative possibilities of product users' participation in the design process. Here, we contrast users as partners (as in Scandinavian participatory design research) and users as subjects (as in use-centered design, which focuses on usability) $[9,10]$.

In the field of design, cooperation is seldom conceptualized. Instead, it is usually assumed that cooperation takes place when several people participate in design, especially if they are in the same place. There are also studies which focus on the cooperation process by examining participants' satisfaction with the process, with their own contribution and with the outcome, as well as enablers of sharing understanding [2,9].

Mobile work machines are specialized and complex machines that operate in demanding environments such as mines, forests, construction sites and harbors. These machines are operated by a human driver. Therefore, a cabin is needed to protect the driver from unsafe and unhealthy conditions. 
The cabin should provide a safe and pleasant working environment for the human driver for enabling the accomplishment of various work tasks.

The cabin of the mobile work machine is a very special part of the machine. Due to this, the mobile work machine and its cabin are usually designed in different companies. Cabin design requires exceptional co-design between engineers and designers, in both companies. There are numerous potential tradeoffs such as visibility, functionality, ergonomics, safety, and industrial design that need to be considered. In practice, for ensuring an acceptable cabin design, a full-size mock-up is needed. This inspection is done by engineers and designers from both companies. In addition, the main customer may participate in this activity.

The mobile work machine industry is a significant business sector in Finland. It is characterized by high demands in design, together with small-scale production series. Cabin design is an especially suitable example for considering development of virtual reality (VR) technology because a cabin is a very limited space, including plenty of important details. Therefore, the cabin model needs to be seen in the right size and from different aspects. In addition, it is important to be able to move inside the model. Furthermore, several people need to be able to share their ideas and impressions of the design.

The mobile work machine industry in Finland wanted to replace their previously used physical mockups by virtual models due to their advances and due to industry's general trend towards digital product process. Individual companies wanted to learn, and get experiences on VR technology applied to cabin design with author's research group in different research projects during the last decade. This activity started after discussions with industry partners, who expressed a need for it. Number of different VR setups were developed by author's research team and this paper is based on these studies.

This paper discusses diffusion of VR technology innovation through the lens of Rogers' theory [11]. The development is studied by using the case of using VR for cabin design in Finland. The development is studied by focusing on innovation itself, i.e., the development of VR technology, economical aspect, which outlines the benefits and costs of using VR, and finally general attitudes and expectations, which outlines the changes in social norms.

\section{Theoretical Background-Diffusion of Innovation}

Diffusion of innovation is a theory that seeks to explain how, why, and at what rate new ideas and technology spread. Diffusion is the process by which an innovation is communicated over time among the participants in a social system. Four main elements influence the spread of a new idea: the innovation itself, communication channels, time, and a social system. Within the rate of adoption, there is a point at which an innovation reaches critical mass [11].

In this paper the above four elements are:

1. Innovation itself is virtual prototypes

2. Communication channels are the industrial communication, as professional journals and conferences

3. Time is the last and coming decades

4. Social system is the norm of design practice within machine design industry

There are five categories of adopters based on the market share of the innovation. As time goes by, new groups adopt the innovation. The adopter groups are presented in Figure 1, and they are [11]:

- Innovators are willing to take risks. They adopt technologies that may ultimately fail.

- Early adopters are opinion leaders.

- Early majority adopt the innovation when the risks are not high anymore.

- Late majority adopt an innovation after the average participant. They are typically skeptical about an innovation.

- Laggards are the last to adopt an innovation. They typically focus on traditions but have low financial liquidity and low social status. 


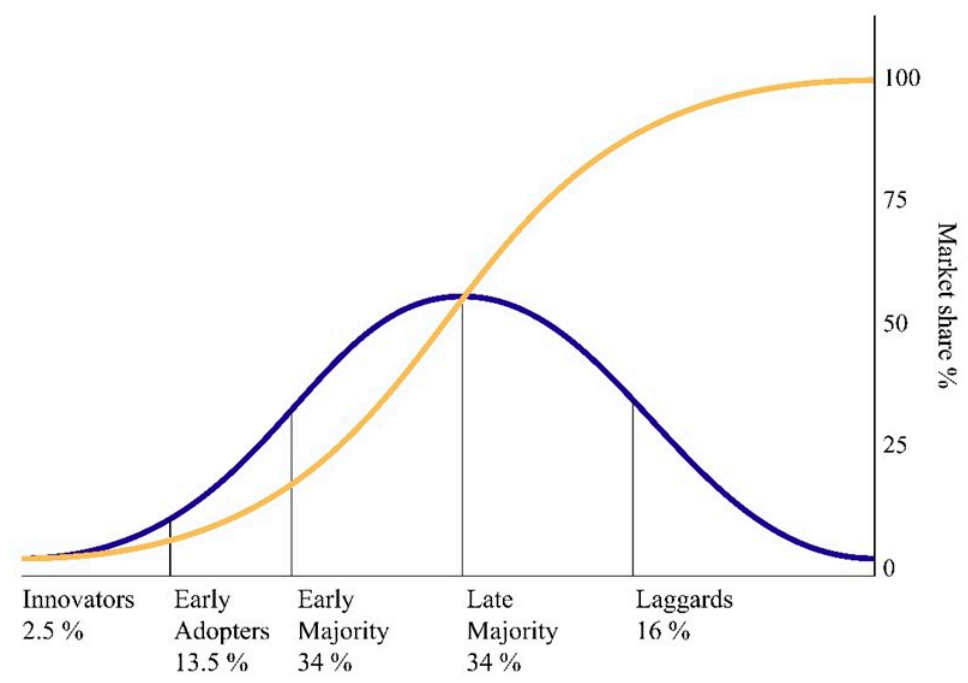

Figure 1. Division of alternative adopters of an innovation and their market share [11].

Potential adopters evaluate an innovation on its relative advantages, its compatibility with the pre-existing system, its complexity or difficulty to learn, its trialability or testability, its potential for reinvention, and its observed effects. These qualities interact and are judged as a whole. For example, an innovation might be extremely complex, reducing its likelihood to be adopted and diffused, but it might be very compatible with a large advantage relative to current tools. Even with this high learning curve, potential adopters might adopt the innovation anyway [11].

Benefits of an innovation are the positive consequences, while the costs are the negative. Costs may be monetary or nonmonetary, direct or indirect. Direct costs are usually related to financial uncertainty and the economic state of the actor. Indirect costs are more difficult to identify. An example would be the need to buy a new kind of pesticide to use innovative seeds. Indirect costs may also be social, such as social conflict caused by innovation [12].

\section{Practical Background-Mobile Work Machines}

Mobile work machines are complex entities which operate in demanding environments such as mines, forests, construction sites and harbors. The function of the cabin is to protect the human driver from unsafe and unhealthy situations such as falling objects, noise, vibration, extreme temperature, and moisture. On the other hand, the cabin should provide a safe and pleasant working environment to enable the accomplishment of various work tasks.

The cabin of the mobile work machine is a very special part of the machine. Due to this, they are typically designed and manufactured by specialized companies. These companies are mostly of medium size, which limits the effort they can provide to the design project. The cabins are individually designed for each new work machine model.

The cabin is positioned on the base of a mobile work machine. Therefore, a lot of communication is needed between the engineers and designers of both companies. Designing a cabin for a mobile machine is challenging in itself because it necessitates numerous trade-offs between various design qualities, such as visibility, functionality, ergonomics, safety, and industrial design $[13,14]$. For example, operators' acceptance of the cabin design depends on the issues of functionality, especially of visibility, but also on considerations related to comfort (e.g., wide enough cabin), ergonomics (e.g., machine operator's work position in the cabin) and aesthetics (machine's appearance and the clarity of its user interface).

For ensuring an acceptable cabin design, an inspection is carried out by engineers and designers from both companies. The main customer (representing the machine operator company) may also be included. Although engineers are usually experienced and understand CAD models, not all the test people are. Therefore, a full-size mock-up is needed. The cabin, in many cases, is very tight, 
and therefore it is essential that an exact prototype be created. The inspection ensures that the cabin offers sufficient visibility to perform the defined work tasks. The visibility is usually restricted by a part of the machine, such as the boom mechanism, the position of which is altered for different work tasks.

\section{Technological Development}

One element in the diffusion of innovation is innovation itself [11]. Our case is focused on creating and presenting prototypes for co-design. The used innovation is virtual environment (VE) technology. Technological development of VE is divided into three main phases: CAVE-like virtual environment, Mini-CAVE, and head-mounted displays (HMD).

\subsection{CAVE-Like Virtual Environment}

The CAVE-like virtual environment (CAVE) is an immersive walk-in VE where stereo-projectors reflect 3D images to three to six walls inside of a room-sized cube. A motion capture system records the real-time position of the user, and 3D images are generated according to his/her position. This gives the user a strong feeling of moving inside a 3D image. Projectors positioned outside the CAVE create a visual display. Mirrors are often used to reduce the distance required from the projectors to the screens. Clusters of desktop PCs are typically used to process the graphics data.

The first CAVE-like virtual environment was invented by Cruz [15]. Since then, many universities and research institutes have established their own virtual reality centers. In our studies, we used the virtual reality laboratory of Seinäjoki University of Applied Sciences, Finland, shown in Figure 2. This CAVE-like virtual environment with five sides was established in 2005 and closed down in 2018. It was a generic virtual reality laboratory for various purposes. Thus, the environment, where the technology is present, is very laboratory-like and fixed to one place.

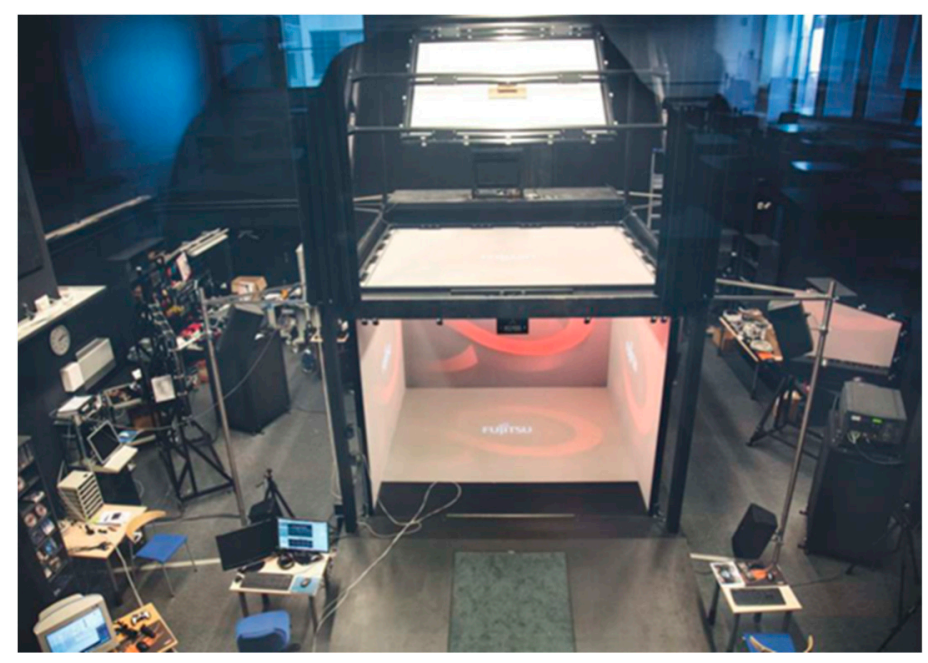

Figure 2. CAVE-like virtual environment at Seinäjoki University of Applied Sciences.

The first attempts to apply this environment to cabin design were not encouraging. First, converting a CAD-model to virtual reality platform software proved to be difficult. We needed to perform several conversion steps, which resulted in conversion errors. These errors needed to be corrected manually, which took time and money. Second, this virtual environment was equipped with a magnetic tracking system, which was not precise enough at boundary areas. We encountered additional problems when we included some physical parts of the cabin in virtual testing. Many of these items, the bench and the control devices among them, caused magnetic disturbances and thus local errors in the tracking system, which increased the unreliability of our virtual cabin testing system. This issue was solved some years later when optical tracking systems became available. 
At the beginning, the computer graphics cards were not powerful enough to render CAD models in real time. This resulted in disturbances, such as blinkering, of the model. This issue was solved later by the technological development of game graphics cards. One of the lessons learned was to simplify the CAD-models before rendering them.

Obviously, VR technology was not ready for cabin design in 2005. However, a number of companies wanted to try it once, in order to get an idea of the possibilities of this technology. Due to several issues within this technology, none of the companies wanted to continue using it. Indeed, VR technology was not competitive with physical prototypes at that time. About five years later in 2010, software and hardware in VR technology was developed enough to get first cabin designs successfully completed in the technical sense. However, the high operating cost and geographical location of the Cave environment made extensive use of it for cabin design unprofitable.

\subsection{Mini-CAVE}

High costs of space and maintenance of CAVE-like virtual environments made many VR laboratories consider more economic alternatives. At the same time, technological development in the game and home cinema industry introduced powerful and inexpensive components that could be applied to virtual reality.

Short-focus 3D projectors, game graphics cards and interface devices enabled the construction of low-cost virtual environments, mini-caves as shown in Figure 3. It was constructed by our research team in 2011. This setup consisted of three back projection screens with short-focus active-stereo projectors, an optical tracking system, one PC and two graphics cards. The setup was constructed especially for virtual testing of cabins in mobile machines. It included components such as the bench and control devices from a real machine.

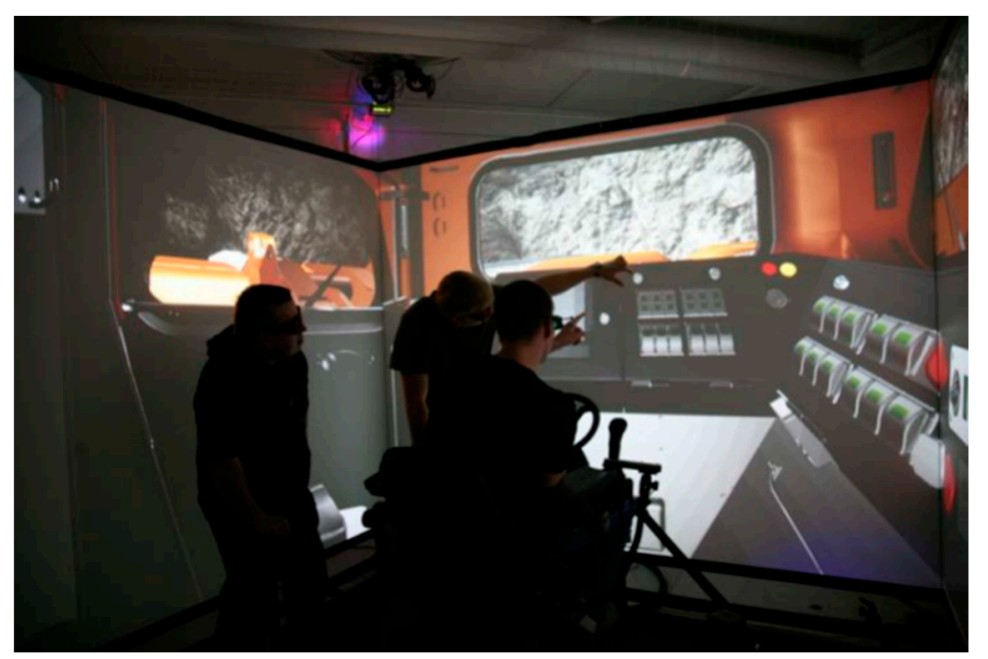

Figure 3. Mini CAVE-like virtual environment at the Tampere University of Technology.

Due to successful experiences with this virtual environment, several companies purchased their own mini-Cave virtual environment, considering this facility to be part of their core business. Several small VR technology companies started to apply this technology and sell VR services for principal companies. Also, a section of this research team founded a spin-off company, and a lot of this activity shifted to a commercial phase.

Another inexpensive immersive display system was presented by Lokki [16]. The system consists of two passive stereo screens and optical tracking. The advantage of this implementation is that its space cost is almost zero, as it can be integrated as a part of an ordinary meeting room (Figure 4). 


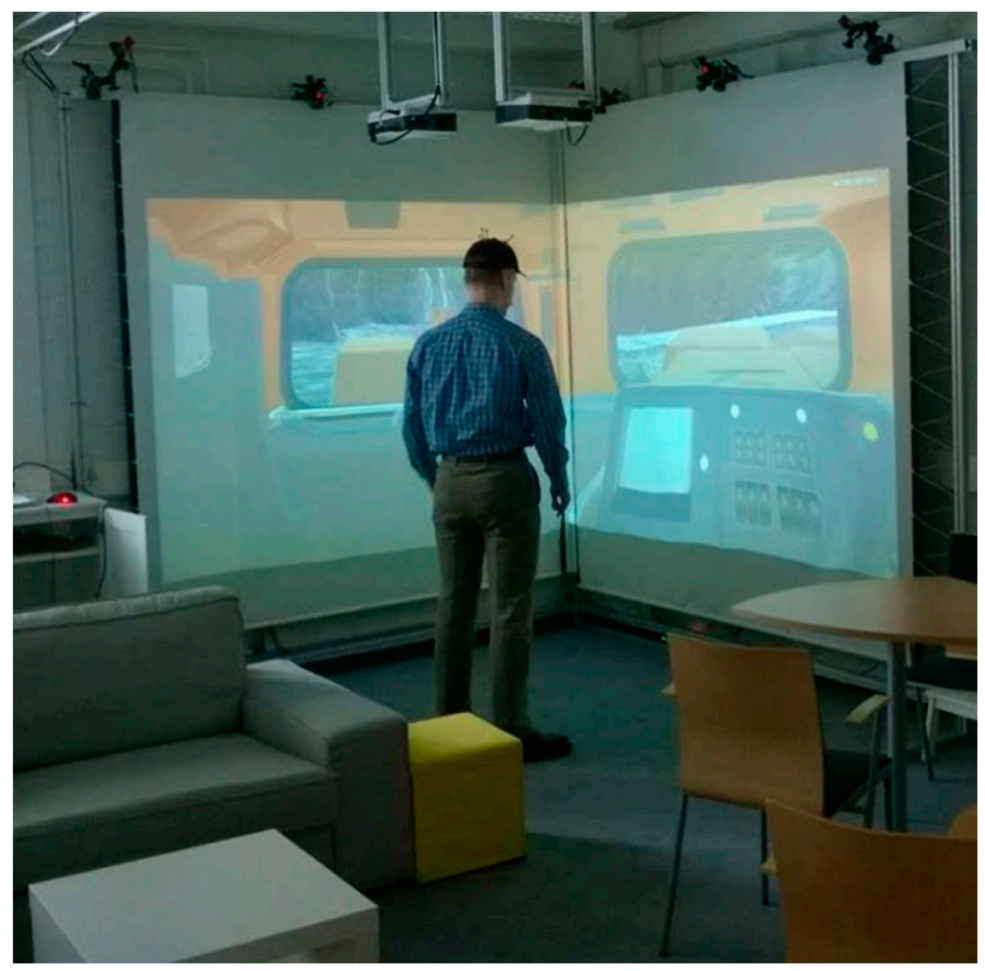

Figure 4. Upponurkka VE at the Tampere University of Technology.

\subsection{Head-Mounted Display}

Head-mounted displays (HMD) have been recently developed into consumer products. There are several products, such as Oculus Rift and Microsoft HoloLenses, which offer good quality 3D vision with head tracking. An HMD device together with well-supported integration with the Unity game engine software forms a good platform for visual inspection of 3D models. Recently, third party plug-in software has become available, enabling easy conversion between CAD-models and the Unity game engine. Therefore, converting CAD-models to game environment is no longer problematic.

HMD devices bring a new dimension for visual inspection of 3D models. An HMD device is not fixed to one place. It can be easily moved, which enables virtual testing to take place in the field. This is a crucial aspect to us, having found out in our earlier studies the importance of the place in virtual testing $[17,18]$.

A major shortcoming with an HMD device is that the test person does not see the other people around him/her. Furthermore, other people cannot see the test person's gestures and have eye contact. Fortunately, the field of vision of the test person can be shown on the screen to other participants, as shown in Figure 5. This setup makes it possible to perform co-design with this technology.

One totally new technological opportunity is to use telepresence with avatars to study cabins in virtual reality. Technologically this is possible but at the moment companies are culturally not ready to communicate with this technology. 


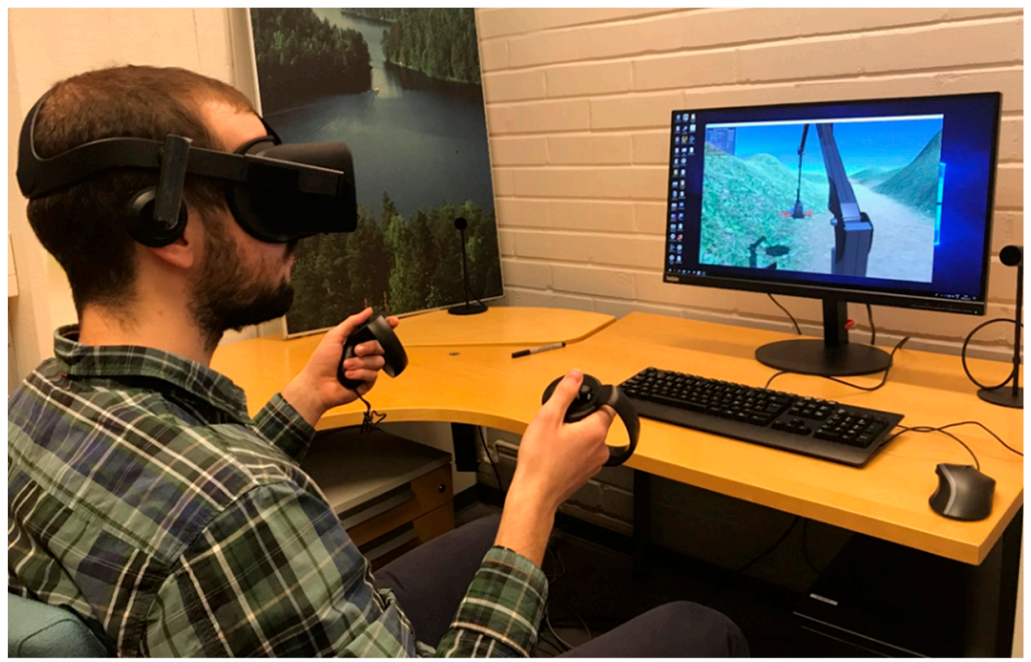

Figure 5. Head-mounted display with personal computer (PC).

\section{Economical Aspects}

In diffusion of innovation, its benefits and costs are essential [11]. Companies' capability of using new tools and technologies for a specific design purpose is very much dependent on the ratio between the advantages and disadvantages (often the cost) related to their use. In the case of the cabin of a mobile machine design, the issue at first hand was that of replacing physical mockups with virtual prototypes. The advantage of this is saving time and money.

The authors' research group has done applied research on VR technology with a number of mobile machine manufacturing companies for over a decade since 2003. During this period, we implemented a number of different VR setups [17] and studied several aspects of immersion [18], which influence user experience in cabin design. The economical aspects presented in Figures 6-8 are based on these observations.

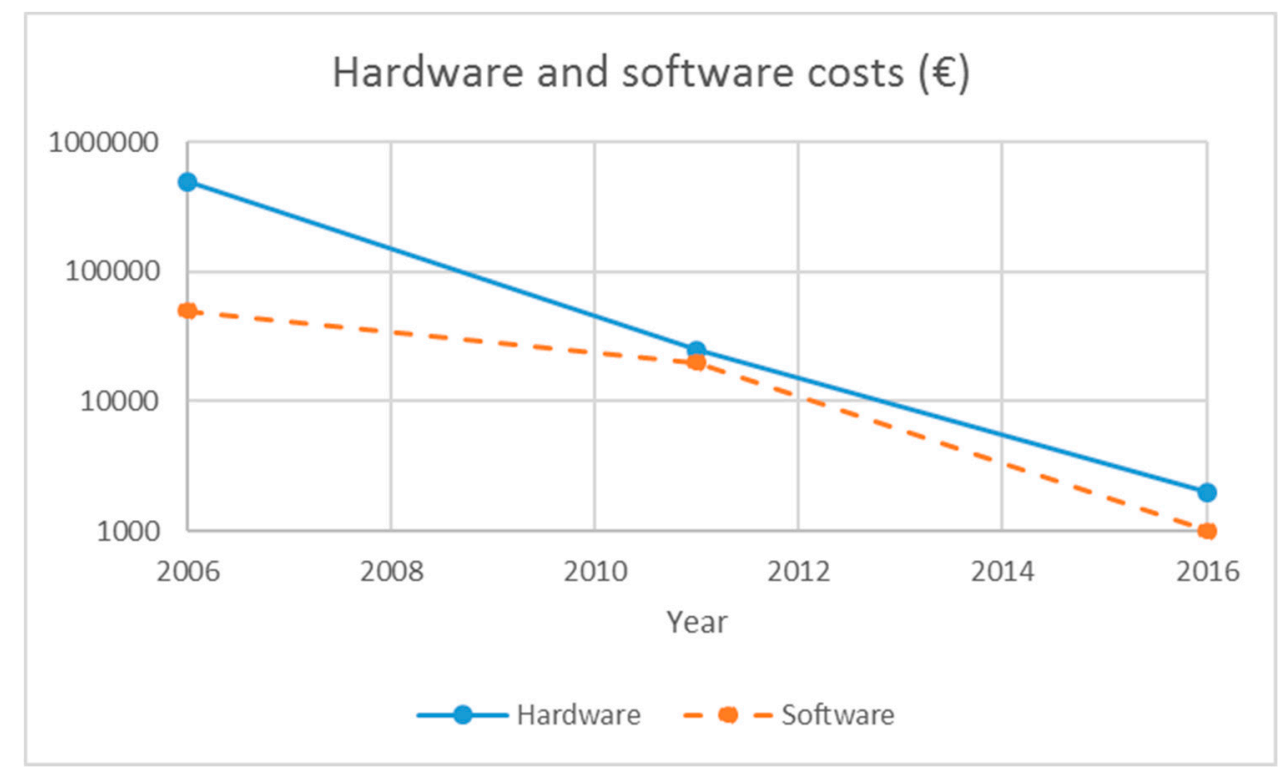

Figure 6. Development of hardware and software costs over a decade. 


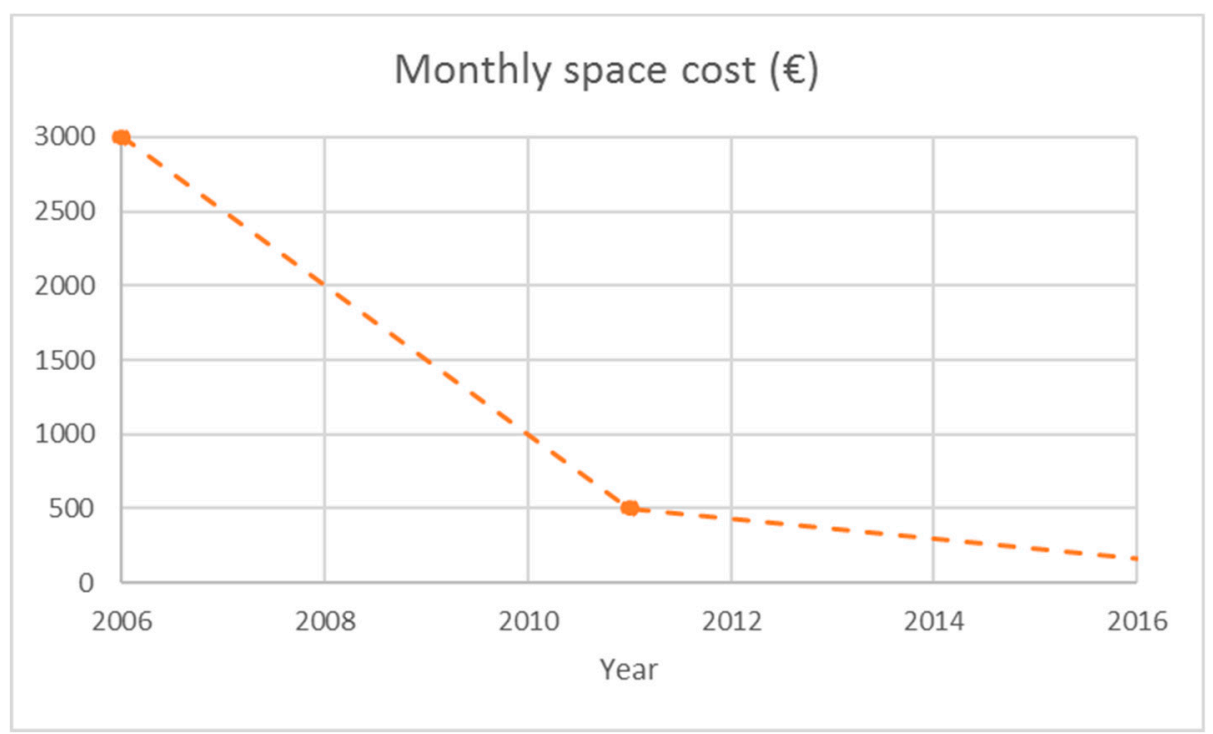

Figure 7. Monthly space cost of a virtual environment.

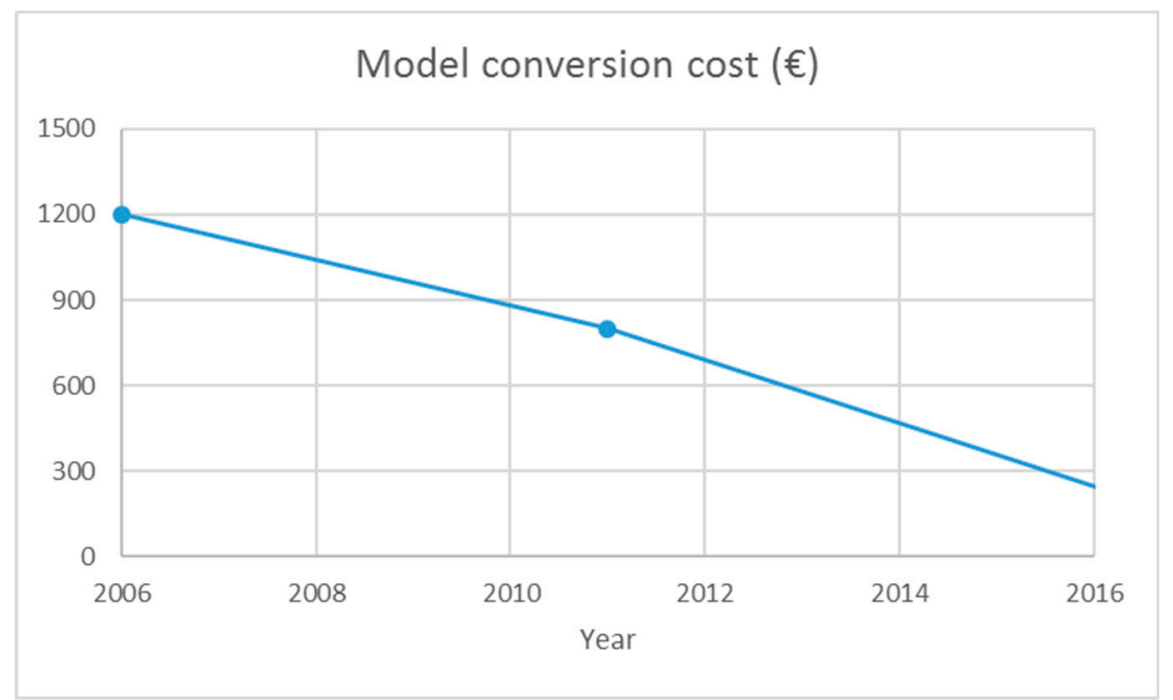

Figure 8. Model conversion cost from computer-aided design (CAD) to virtual environment.

The cost of using virtual reality technology consists of at least three different outlays: hardware, software and space expenses. At the beginning of the study period (2006), both hardware and software expenses were high. Virtual reality was generally considered hi-tech, and its market was limited. This resulted in high prices for these products. However, rapid technological development, especially the emerging game and home cinema technology, has decreased these expenses logarithmically even, as shown in Figure 6.

Space cost has also been an important issue as a CAVE-like virtual environment requires a lot of space around it. This space does not need to be exceptionally high; the implementation of floor and roof projection requires extra space under and above the Cave, though. Space cost has not changed much over a decade, and this has been one of the reasons why many institutions have given up on the maintenance of their CAVE-like virtual environments. Technological development, especially short-focus projectors and head-mounted displays, have enabled the construction of virtual spaces with reduced space cost, as shown in Figure 7. One solution for solving the issue with space cost is to integrate virtual space as a part of a conventional meeting room as shown in Figure 4 [16].

Presenting CAD-models in virtual environments has been a well-known issue. In CAD systems, the models are defined in a mathematical form, and for a virtual environment they need to be converted 
into a huge cloud of polygons. CAD software has not supported this possibility until now. Especially in the past, this conversion required a lot of manual work. This phase incurred both labor cost and caused delay in the inspection of cabin models, as shown in Figure 8. Today, this is not an issue anymore.

\section{General Attitudes and Expectations}

One element in diffusion of innovation is social norm. Innovators are the first to start using an innovation and they do so in such a stage when the technology is not stable and there are big risks [11]. With the virtual technology that was the use of CAVE-like virtual environment, which was expensive, and the implementing tools were inchoate. When the diffusion process proceeds the benefits are commonly known, costs are becoming lower and the risks of failing are decreasing.

Expectations towards virtual reality technology have crystallized during a decade. In 2007, virtual environments were at the top of Garden's hype curve [19]. These expectations affected also managers of mechanical engineering companies. Several companies were keen to see what can be done with this technology. However, none of them seriously considered using virtual reality technology in their own activities.

A major change in Finnish companies took place around 2010 when low-cost virtual technology became available. In addition, several spin-off companies offering virtual environment solutions were established. Several companies purchased their own virtual environments as they considered virtual testing to be part of their core business.

Virtual reality reached a more stable phase in Gartner's hype curve of 2016 [19]. It is still not considered as a fully productive technology, and the expectation for this to happen is within five to ten years. Virtual reality market is expected to grow exponentially within the next decade [20]. The major growth is expected to take place in the gaming area but also in several other market areas.

\section{Discussion}

Diffusion of innovation includes four elements which are innovation itself, communication, time and social norm [11]. In this paper we hardly dealt with the communication. In practical research projects, it was present as the projects implemented trial which the industry needed, so practical professionals got ideas what could be done with VR for cabin design.

In this paper, innovation itself and time were presented together; that was how VR technology and virtual prototypes have been developed during the last decade. There are several differences between alternative technologies when they are used for engineering design purposes. These properties are summarized in Table 1.

Table 1. Comparison of the properties in the alternative VEs.

\begin{tabular}{|c|c|c|c|}
\hline & CAVE-Like VE & Mini CAVE-Like VE & Head-Mounted Display \\
\hline Device type & generic & customized & generic \\
\hline $\begin{array}{l}\text { Virtual-mixed } \\
\text { — physical axel }\end{array}$ & $\begin{array}{l}\text { focus on visualization, } \\
\text { physical components } \\
\text { might be possible }\end{array}$ & $\begin{array}{l}\text { focus on visualization } \\
\text { with physical } \\
\text { components }\end{array}$ & $\begin{array}{l}\text { focus on visualization; } \\
\text { physical components not } \\
\text { possible }\end{array}$ \\
\hline Price of the set-up & about $500,000 €$ & about $25,000 €$ & about $1000 €$ \\
\hline Space type & laboratory & meeting room & placeless, movable \\
\hline Price of the space & about $1200 € /$ month & about $700 € /$ month & about $10 € /$ month \\
\hline Assumption & expensive, rigid & customized & $\begin{array}{c}\text { inexpensive, flexible, } \\
\text { game-like }\end{array}$ \\
\hline Cooperation limits & $\begin{array}{l}\text { the participants in the } \\
\text { same space, but focusing } \\
\text { on the screen }\end{array}$ & $\begin{array}{l}\text { the participants in the } \\
\text { same space, but focusing } \\
\text { on the screen }\end{array}$ & $\begin{array}{l}\text { the one with head } \\
\text { mounted display does } \\
\text { not see others }\end{array}$ \\
\hline
\end{tabular}


The main difference between the alternative VEs in the cooperation situation is the presence in the same space. In CAVE-like VE and mini-CAVE, all participants are in the same space, see others, and the same virtual image. Whereas, when using HMD the user is isolated from other participants, seeing only the virtual image, not the physical world. However, the HMD image can be presented on screen to other participants, and they all can discuss the product prototype. In this case, the user does not see the non-verbal communication. Indeed, in CAVE-like VEs, the participants can see the others, but probably they focus on the screen in which the virtual prototype is presented, and so their attention to others' non-verbal communication might remain deficient.

When using an HMD, the user sees only the virtual images, without any visual view to the physical world, as the horizon. For some users, this can cause dizziness, which is also evidenced by their vague way of walking when equipped with the HMD. However, this is not that different to other kinds of VEs. It is known that immersed in CAVE-like VE technology, some users tend to exhibit symptoms similar to those of classical motion sickness both during and after the VE experience. This type of sickness, cybersickness, is distinct from motion sickness in that the user is often stationary but has a compelling sense of self-motion through moving visual imagery [21].

One difference between the alternative VEs is the kind of a place the virtual prototypes are presented in alternative VEs, as shown in Table 1. The place in which virtual prototypes are evaluated and discussed affects the interpretations of them [22]. The place of CAVE-like VE is a laboratory in which users focus on science and technology [17], not on the products [22]. The alternatives are better in this respect. The mini CAVE-like VE can be built in a meeting room, which is the traditional place of evaluation and negotiation of product prototypes. Furthermore, HMDs are movable, so that they can be used anywhere [23].

The fourth element of diffusion of innovation is social norm. It includes how well-known the use practice and the benefits of an innovation are [11]. In our case the innovation is the use of virtual prototypes with VE. There have been three different technical solutions which have become accessible for use in cabin design consecutively. Some design cases have adopted all of them, either for temporary or more permanent use. When a new technological solution with more benefits and lower costs has become available more users have appeared. Figure 9 summarizes our experiences with development of usage of virtual reality technology in Finnish mobile work machine industry.

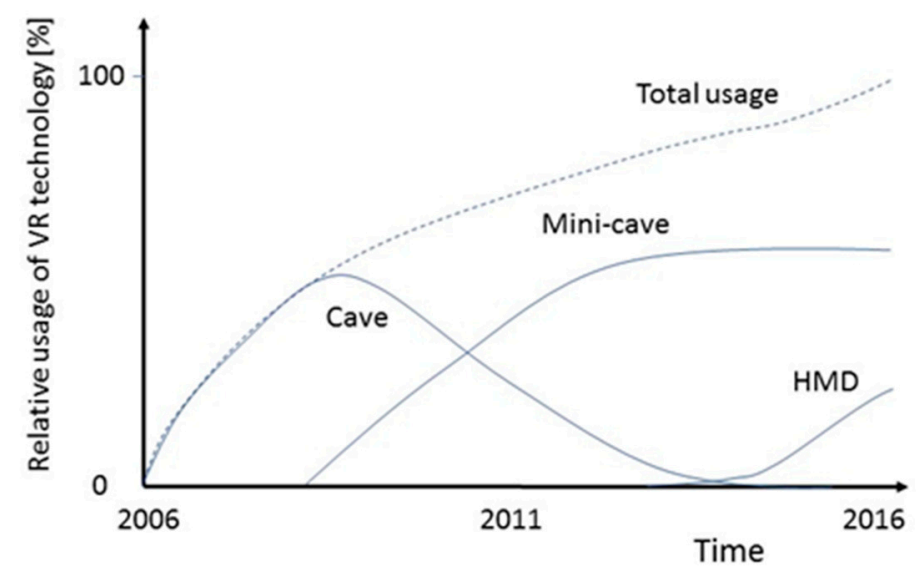

Figure 9. Development of usage of virtual environments in cabin design in Finnish mobile work machine industry.

Author Contributions: A.E. has supervised the research work. T.T. has done conceptualization, A.E. and T.T. wrote the paper.

Funding: This research received no external funding.

Conflicts of Interest: The authors declare no conflict of interest. 


\section{References}

1. Davidson, A.L.; Schofield, J.; Stock, J. Professional Cultures and Collaborative Efforts: A Case Study of Technologists and Educators Working for Change. Inf. Soc. 2001, 17, 21-32.

2. Kleinsmann, M.; Valkenburg, R. Barriers and Enablers for Creating Shared Understanding in Co-design Projects. Des. Stud. 2008, 29, 369-386. [CrossRef]

3. Bereiter, C.; Scardamalia, M. Surpassing Ourselves. An Inquiry into the Nature and Implications of Expertise; Open Court Publishing Company: Chicago, IL, USA, 1993.

4. Yang, M.C.; Epstein, D.J. A study of prototypes, design activity, and design outcome. Des. Stud. 2005, 26, 649-669. [CrossRef]

5. Prahalad, C.K.; Ramaswamy, V. Creating Unique Value with Customers. Strategy Leadersh. 2009, 32, 4-9. [CrossRef]

6. Di Gangi, P.; Wasko, M. Open Innovation through Online Communities. In Knowledge Management and Organizational Learning; Kind, W.R., Ed.; Springer: Boston, MA, USA, 2009; pp. 199-213.

7. Tiainen, T.; Ellman, A.; Kaapu, T. Workers' tacit knowledge transferred to conceptual design: The case of mobile work machine. In Proceedings of the Boundary-Crossing Conference on Co-design in Innovation, Espoo, Finland, 17-19 June 2013; pp. 709-720.

8. Sleeswijk Visser, F.; Stappers, P.J.; van der Lugt, R.; Sanders, E.B.-N. Contextmapping: Experiences from Practice. CoDesign 2005, 1, 119-149. [CrossRef]

9. Steen, M. Tensions in human-centred design. CoDesign 2001, 7, 45-60. [CrossRef]

10. Sanders, E.B.; Stappers, P.J. Co-creation and the new landscaper of design. CoDesing 2008, 4, 5-18.

11. Rogers, E.M. Diffusion of Innovations, 1st ed.; Free Press of Glencoe: New York, NY, USA, 1963.

12. Wejnert, B. Integrating models of diffusion of innovations: a conceptual framework. Annu. Rev. Sociol. 2002, 28, 297-326. [CrossRef]

13. Ellman, A.; Laitinen, J.; Tiainen, T. Combination of Virtual and Physical Objects in User-centered Design of Mobile Work Machine Cabin. In Proceedings of the IMECE2007, ASME International Congress and Exposition, Seattle, WA, USA, 11-15 November 2007.

14. Tiainen, T.; Ellman, A.; Kaapu, T. Three Frames for Studying Users in Virtual Environments: Case of Simulated Mobile Machines. In Proceedings of the International Symposium on Distributed Simulation and Real Time Applications (DS-RT 2011), Manchester, UK, 4-7 September 2011.

15. Cruz-Neira, C.; Sandin, D.; DeFanti, T.; Kenyon, R.; Hart, J. The CAVE: Audio Visual Experience Automatic Virtual Environment. Commun. ACM 1992, 35, 64-72. [CrossRef]

16. Lokki, T.; Ilmonen, T.; Mäkelä, W.; Takala, T. Upponurkka: An Inexpensive Immersive Display for Public VR Installations. In Proceedings of the IEEE Virtual Reality 2006, Workshop on Emerging Display Technologies, Alexandria, VA, USA, 25-29 March 2006; pp. 15-18.

17. Kuusisto, J.; Kaapu, T.; Ellman, A.; Tiainen, T. Developing VIP2M: A Virtual Environment for Prototyping Mobile Work Machines. In Proceedings of the 12th International Design Conference DESIGN 2012, Cavtat, Croatia, 21-24 May 2012; pp. 657-666.

18. Kuusisto, J.; Ellman, A.; Kaapu, T.; Tiainen, T. Effect of the Immersion Level of a Virtual Loader Simulator on the Sense of Presence. In Proceedings of the ASME 2011 World Conference on Innovative Virtual Reality (WINVR2011), Milan, Italy, 27-29 June 2011.

19. Gartner Company. Available online: www.garner.com (accessed on 10 May 2019).

20. Virtual Reality (VR) Market Analysis by Device, by Technology, by Component, by Application (Aerospace \& Defense, Commercial, Consumer Electronics, Industrial, \& Medical), by Region, and Segment Forecasts, 2018-2025. Available online: https://www.grandviewresearch.com/industry-analysis/virtual-reality-vrmarket (accessed on 10 May 2019).

21. LaViola, J.J., Jr. A discussion of cybersickness in virtual environments. ACM SIGCHI Bull. 2000, 32, 47-56. [CrossRef] 
22. Kaapu, T.; Tiainen, T.; Ellman, A. User Interpretations of Virtual Prototypes: Physical Place Matters. Scand. J. Inf. Syst. 2013, 25, 3-24.

23. Ellman, A.; Tiainen, T.; Tossavainen, A. Evaluating a Virtual Wind Power Park in a Churchyard: A Perception Study with Portable VR Devices. In Proceedings of the ASME International Design Engineering Technical Conferences and Computers and Information in Engineering Conference, 38th Computers and Information in Engineering Conference, Quebec City, QC, Canada, 26-29 August 2018. [CrossRef] 